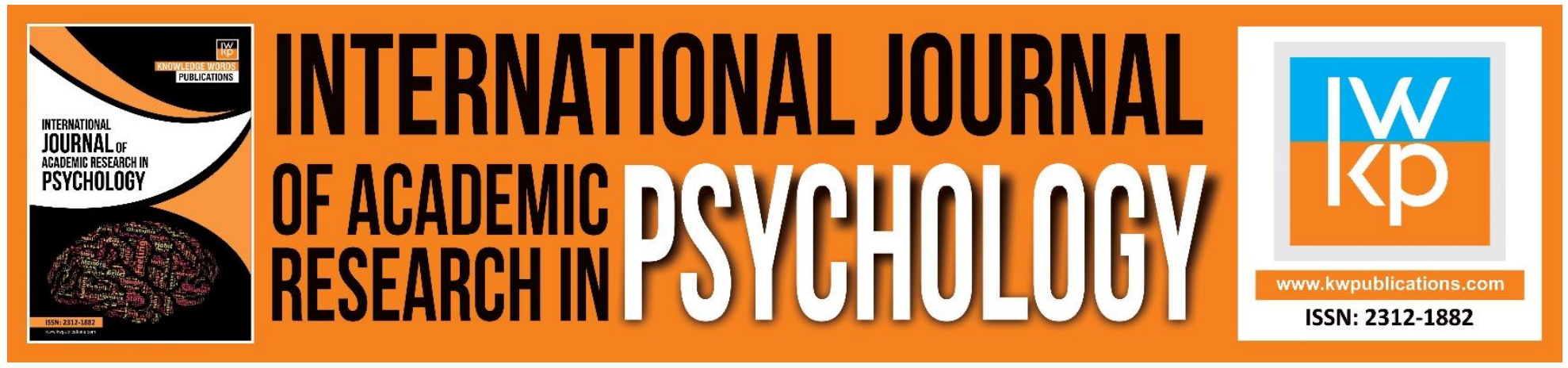

\title{
The Relationship between Organizational Climate, Job Commitment and the Mediating Role of Job Consciousness among the Employees of Islamic Azad University of Yazd
}

Saeed Vaziri Yazdi, Mohammad Hosein Fallah Yakhdani

To Link this Article: http://dx.doi.org/10.46886/IJARP/v2-i1/1719

DOI: 10.46886/IJARP/v2-i1/1719

Received: 02 May 2015, Revised: 13 July 2015, Accepted: 14 April 2015

Published Online: 29 August 2015

In-Text Citation: (Yazdi, \& Yakhdani, 2015)

To Cite this Article: Yazdi, S. V., \& Yakhdani, M. H. F. (2015). The Relationship between Organizational Climate, Job Commitment and the Mediating Role of Job Consciousness among the Employees of Islamic Azad University of Yazd. International Journal of Academic Research in Psychology. 2(1), 42-52.

\section{Copyright: (C) 2015 The Author(s)}

Published by Knowledge Words Publications (www.kwpublications.com)

This article is published under the Creative Commons Attribution (CC BY 4.0) license. Anyone may reproduce, distribute, translate and create derivative works of this article (for both commercial and non-commercial purposes), subject to full attribution to the original publication and authors. The full terms of this license may be seen at: http://creativecommons.org/licences/by/4.0/legalcode

Vol. 2, No. 1, 2015, Pg. 42 - 52

https://kwpublications.com/journals/journaldetail/IJARP

JOURNAL HOMEPAGE

Full Terms \& Conditions of access and use can be found at https://kwpublications.com/pages/detail/publication-ethics 


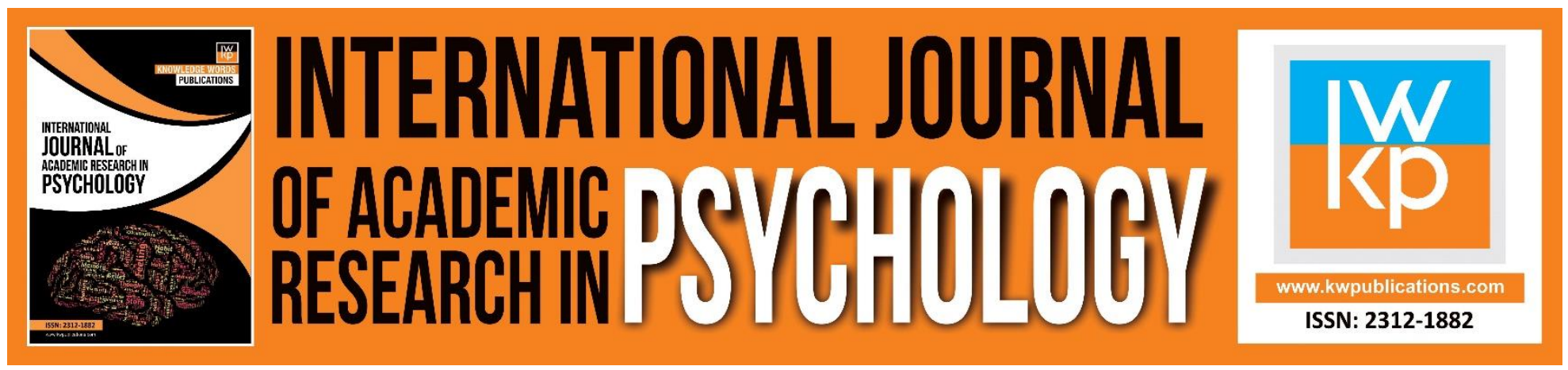

\title{
The Relationship between Organizational Climate, Job Commitment and the Mediating Role of Job Consciousness among the Employees of Islamic Azad University of Yazd
}

\author{
Saeed Vaziri Yazdi, Mohammad Hosein Fallah Yakhdani \\ Department of Educational Sciences, Yazd Branch, Islamic Azad University, Yazd, Iran
}

\begin{abstract}
The purpose of this study was to examine the relationship between organizational climate and job commitment with regard to the role of job consciousness in the employees of Islamic Azad University of Yazd. In this study, the descriptive-correlation method is used, because the main objective was to investigate the relationship between several variables. By the calculation of Cochran, 195 subjects were randomly, and with attention given to the proportions of the population selected for stratified sampling. To collect data for organizational climate Halpin and Croft questionnaire was used, and for the variable of organizational commitment, Allen and Meyer questionnaire and to determine the variable of job consciousness a questionnaire designed by Iraj Soltani was used. The results of the research hypothesis, achieved through stepwise regression and path analysis showed that in the relationship between organizational climate and job commitment, job consciousness has a mediating role. Also Furthermore was a significant relationship between the variables of organizational climate and job consciousness with job commitment $(p<0 / 01)$. The climate of the population for this study had more predictive power than the job consciousness of its employees in connection with employee engagement. The correlation between organizational climate and job commitment in people who have a higher job consciousness is stronger. This is while the importance of structural factors organizational climate can be an effective agent job such as debatable and also overcome the job conscience.
\end{abstract}

Keywords: Organizational Climate, Job Commitment, Job Consciousness, Islamic Azad University.

\section{Introduction}

The most important capital is the human resources and the quality of capital and the higher the likelihood of success, survival and development will be more is organized. One of the job attitudes, organizational commitment is that the statement of the caseis that the employee organization wish to remain in membership of the organization. Organizational commitment means a person, organization knows their representative predicted (Shafiabadi, 2012). 
Previous studies have shown that work experience, organizational factors and individual commitment to act as a background. Risk factors in the development of organizational commitment and its effect on the several aspects of the behavior of employees refers to the following:

-Absenteeism and turnover rates are higher for those with a sense of commitment, lower.

-Those who are more committed, less likely to seek another job to pay.

-Commitment to effort and performance. It means that the employees' commitment to their organization, the more they try to do more for the better (Goodarzi \& Gominian, 2002). Organizational commitment and consensus in the organization is dependent on organizational culture. Somewhere else, the relative degree of organizational commitment as a person's identification with the organization and his involvement and participation has been defined. In this definition, the commitment of three factors:

1- According to the goals and values of the organization

2- Tends to considerable effort to the organization

3- Strong and deep wish to continue membership in the organization.

The owner rational people who really are part of your organization, it will have a greater commitment to increase their efforts and decrease of turnover in them (Birjandi, 2000). One of individual and organizational factors as key factors considered be relevant to organizational commitment, the climate is dominant. Studies show that policies, plans, financial position or shares of any organization suitable working environment does not become, but what makes the company an ideal work environment, employees feel about the environment work. Working conditions for the creation and growth of employees feel summarized in three factors: management, job and colleagues. Over the last few decades of the first definition of organizational climate is going. During this period, various definitions proposed that the essence of all of them in two elements taken:

1. A system of cognitive (mental element), which reflects the value system of the organization.

2. Mass withdrawal (emotional element) of policy, practice and methods of organization arise. The first case is linked to the culture of the Organization and more about the other represent a stream that is associated with the leadership. The atmosphere, the view is a non-visible part of the vision and culture of the Organization, like an iceberg floating in the water. Although thinkers about the definition of organizational climate do not have consensus, but most of its features in the same views have been expressed. (Gardner, 2005; Babai et al., 2006)

Moran and Volkwayne (1992) in their assessment of organizational climate to four point to the following approach: Structural approach:

Organizational climate, organizational structure is considered to be objective. Since the members of the organization share common structural features, find common understanding that climate forms. In other words, organizational climate organizational structure, its objective is that people encounter it and understand it.

\section{Conceptual Approach}

Based on this approach, the basic part of the creation of the organizational climate within individuals people respond to situational variables in ways that are meaningful to them is psychological. Describe the psychological climate of the organization.

Interactive Approach 
INTERNATIONAL JOURNAL OF ACADEMIC RESEARCH IN PSYCHOLOGY

Vol. 2, No. 1, 2015, E-ISSN: 2312-1882 @ 2015 KWP

According to this approach, in response to situations that they face to reach a common agreement that is the foundation of organizational climate. The disadvantage of this approach is that the impact of organizational culture on cooperation and communication among members of the group are not considered.

\section{Cultural Approach}

According to this approach, organizational climate is a result of the interaction of a group of people who share a frame of mind. The disadvantage of this method is that it requires an explanation of the relationship between culture and climate. (Moran and Volkwayne, 1992; Khosravian et al., 2009)

The Faghihi research (2012) entitled "The relationship between climate and organizational commitment of teachers in primary schools for girls in Varamin city" in educational organizations also led to the following conclusions:

1) Level of organizational commitment in schools that have the appropriate climate than schools that do not have good organizational climate are significant, more.

2) The organizational affective commitment in schools that have the appropriate climate than schools that do not have good organizational climate is significantly, remarkably higher. 3) The continuous commitment of organizational climate in schools that are appropriate to the proper climate is significantly schools, remarkably higher.

4) Organizational normative commitment in schools that have the appropriate climate than schools that do not have good organizational climate is significantly, remarkably higher.

According to research by Goleman et al (2001) the impact on the profitability of the organization's excellent climate is one-third and two-thirds of the economic situation and the competitive dynamics. Morris and Bloom (2002) examined the relationship between the position and the results showed that their commitment, culture and climate have a significant influence on employee job satisfaction. In this study, the mediating role of job consciousness in the relationship between climate and organizational commitment was investigated it is not short. Job consciousness, a cultural norm is to do good work in the community, positive spiritual values and believes that the work itself has an intrinsic value (Talebian, 2003).

Essentially labor monotheistic vision of Islam is a value more effort in the work world and the hereafter, about happiness and salvation in this world and the Hereafter provides individuals and their high degree of jihadists in the way of the Lord range. It is necessary to work, subject to compliance with specific requirements including a detailed and comprehensive work to be done. As in the field of the Prophet Muhammad has been narrated as: When do you want it done in a good and comprehensive, because all of these things and applying them to the terminal properly defined and introduced (Majlesi, $1403 \mathrm{AH}$ ).

Incentives and conscientious work of the Iranians, through their rituals and ceremonies for collective work was being formed and has been strengthened. The rituals and synergies in all the structures of life and can not only considered for a job. In fact, the complexity and interaction of these rituals and synergies at all levels of life, the production and reproduction of consciousness have been required to do. All types stories and poems of work, proverbs, tales, different cooperation and other areas of the culture of the people, of the factors of establishing and strengthening the necessary motivation to have work done (Sefidgar, 2009). 
Some examples are found in the oral literature that discouraged job count and delays in work, people are forced to work more seriously. In fact, this type of literature which reflects the viewpoint of society to the unemployed person is, at the same time, it keeps people from unemployment or underemployment and creating an interest, invites him to work. That is a double (a punishment / reward) leads the person to work. Oral literature available in the community, as a collective soul acts. Samples referred to in oral literature and evidence of involvement and interest in the work and the people against the valuations, care work and dedication to the plane. When the collective spirit and determination of such judgments based on people during growth, the values that are intrinsic to them at any time, respect, and more than ever they are attached. In these concepts, there is a kind of valentine society from generation to generation, is under way and people. Interest and interest components that work ethic is an important component in the past, was seen in a variety of workrelated oral literature. Perhaps one of the manifestations of it can be found in work-songs. Music and song includes the lyrics that people read the work (Zolfaghari, 2009).

The context of human research so continuing to investigate the impact of the human factor is widespread. Barati et al (2010) conducted a study on "The relationship between climate and conscience to do with job performance" did the results of path analysis showed that the cooperative atmosphere and innovative atmosphere reliability directly but indirectly to job performance their nose. The results of this study were: consciousness affects job performance. The positive climate could increase this effect. Thus, organizations and managers can evaluate the personality traits of their employees, especially their consciousness, to create a positive atmosphere in the organization use. Archana study (2004) showed that social support and control as well as job stress and there is consciousness. This means that people with high consciousness always concerned with work, job and their duties are correct. This mainly concerns and how supervision and discipline of the society and the organization of individual stems.

Since the objective of this study was to investigate the role of mediator in the relationship between climate and organizational commitment is job consciousness in Figure (1) the basic model of the relationship between variables is given. For this purpose, the theoretical assumption as the model assumed that after evaluating the relationships among the variables, parameters, and finally model is estimated:

\section{Figure1. Theoretical and Conceptual Model of the Relationship between Variables Methods}

The study is a correlation study conducted by stepwise regression analysis and path analysis were used. The population in this study were all 397 employees Azad University of Yazd in 2013, the 195 subjects were randomly selected and classified in accordance with the proportion of the population, were surveyed. In order to collect information on the main variables in this study, questionnaires were used as follows: 
1. In the case of climate variables: organizational climate questionnaire Halpin and Croft. Eight behavioral dimensions of organizational climate questionnaire that staff and managers, including team spirit, harassment, interest, intimacy, observant, getting away, the influence and dynamism and the emphasis on production is in the back. The questionnaire was

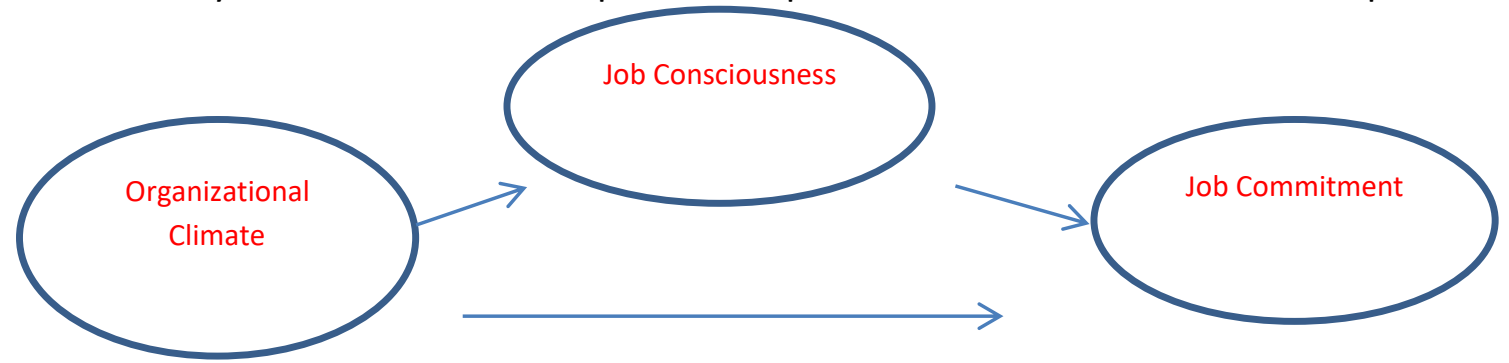

standardized in 1995 by Doshmanziare and its validity is confirmed (Rostamkolai et al., 2013); Faghihi (2012) as: "The relationship between climate and organizational commitment among female primary school teachers Varamin city" of Cronbach's alpha was calculated for 0.81 reliability climate.

2. For variable organizational commitment, organizational commitment of Allen and Meyer questionnaire. The questionnaire includes 24 questions on three dimensions of organizational commitment standards and affective commitment, continuous commitment and normative commitment or duty. Organizational commitment questionnaire has been a standard and reliable and have been used by local researchers and its validity and reliability have been measured (Rostamkolai et al., 2013); Seidameri and Esmaeeli research (2009) entitled: "The relationship between empowerment, organizational commitment, and job commitment Physical Education Department of Tehran Province" the questionnaire reliability through Cronbach's alpha coefficient was estimated the value of 0.83 .

3. In order to determine the variable job consciousness: questionnaire design conscience by Iraj Soltani. The validity of the internal control tools in research and has been approved by experts. In a study titled, "The effect of transformational leadership style of leadership and engagement on the consciousness of teachers" Hassanzadeh et al. (2010) Inter-rater reliability of the questionnaire through Cronbach's alpha coefficient was estimated the value of 0.80 .

To organize and summarize the data descriptive statistics (Mean, Standard Deviation and so on) was used to examine the relationship between variables in inferential statistics stepwise regression was used. Then researchers through Structural Equation Modeling and pattern using the EQS software to review and validate the proposed model and analysis of the issue.

\section{Results}

The sample consisted of 195, 133 men (equivalent to $2.68 \%$ ) and 62 women (at $31.8 \%$ ). Furthermore, as a field of activity, number 60 in the area of financial administration (30.8\%), 18 educational affairs (2.9\%) of 31 patients (15.9\%) and 22 student affairs (11.3\%), 6 construction (1.3\%), 3 culture (5.1 $\%), 16$ School of Medicine (2.8\%), the university hospital 34 patients (17.4

$\%)$ and 5 of Prefecture (6.2\%) were selected. In terms of employment status, the number 167 (the equivalent of $6.85 \%$ ) officially and 28 (at 14.4 percent) were in the form of a treaty. The number and proportion of the respective proportions of the study population were just like. The most appropriate 


\section{INTERNATIONAL JOURNAL OF ACADEMIC RESEARCH IN PSYCHOLOGY}

Vol. 2, No. 1, 2015, E-ISSN: 2312-1882 @ 2015 KWP

statistical model to test and verify the hypothesis of this study, stepwise regression analysis and path analysis test was considered. The values in Table 1 showed that the job consciousness with organizational climate $(p<0 / 01, r=0 / 72)$ as well as job commitment $(p<0 / 01, r=0 / 8)$ has a significant positive relationship. In addition, between organizational climate and job commitment $(p<0 / 01, r=$ $0 / 91$ ) is also a significant positive correlation.

Table1. The Mean, Standard Deviation and Internal Correlation between variables

\begin{tabular}{|c|c|c|c|c|c|}
\hline Row & Variables & Mean & Standard deviation & 1 & \\
\hline 1 & Job consciousness & $161 / 67$ & $68 / 5$ & - & \\
\hline \multirow[t]{3}{*}{2} & Organizational climate & $72 / 83$ & $24 / 37$ & $0 / 72 *$ & - \\
\hline & 3 Job Commitment & $77 / 6$ & $30 / 67$ & & $0 / 8^{*}$ \\
\hline & $0 / 91^{*}$ & & & & \\
\hline
\end{tabular}

In Table 2, we see that the organizational climate standard Beta coefficient equal to 0/91, \% 82/8 of the variance of job consciousness is explained. Job conscious and organizational climate respectively, with standard Beta coefficients equal to $0 / 69$ and $0 / 3, \% 87 / 1$ of the variance in job commitment has been explained.

Table2. The results of Structural Equation Modeling

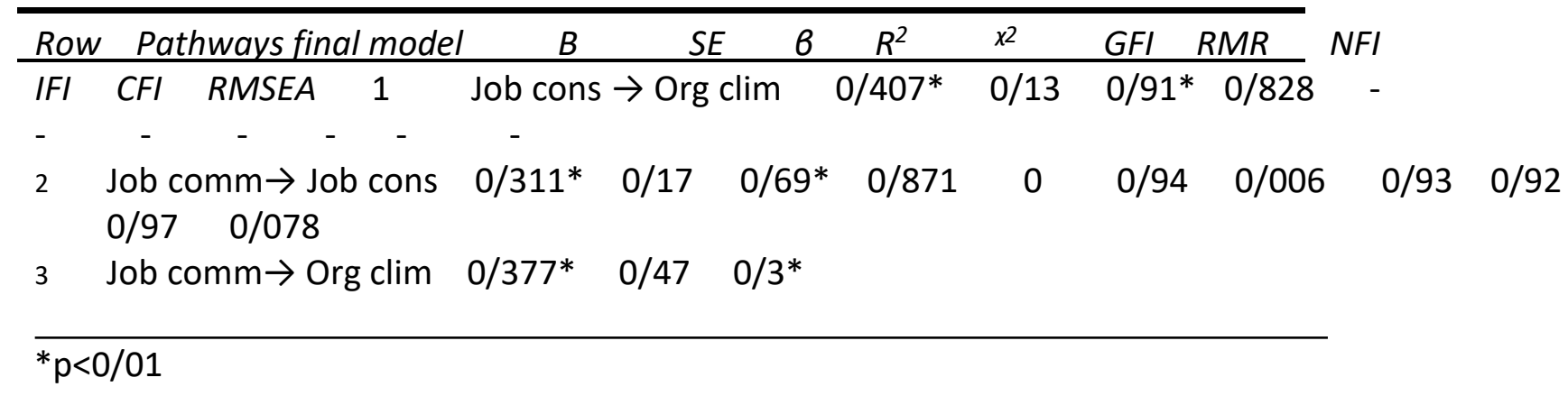

Based on these data and the results of them can be the ultimate pattern research of the relationship between the variables that confirms the hypothesis put forward in this study can also be traced to the following and complete:
$0.91^{*}$
$0.69 *$

$(87 / 1)$ 
INTERNATIONAL JOURNAL OF ACADEMIC RESEARCH IN PSYCHOLOGY

Vol. 2, No. 1, 2015, E-ISSN: 2312-1882 @ 2015 KWP

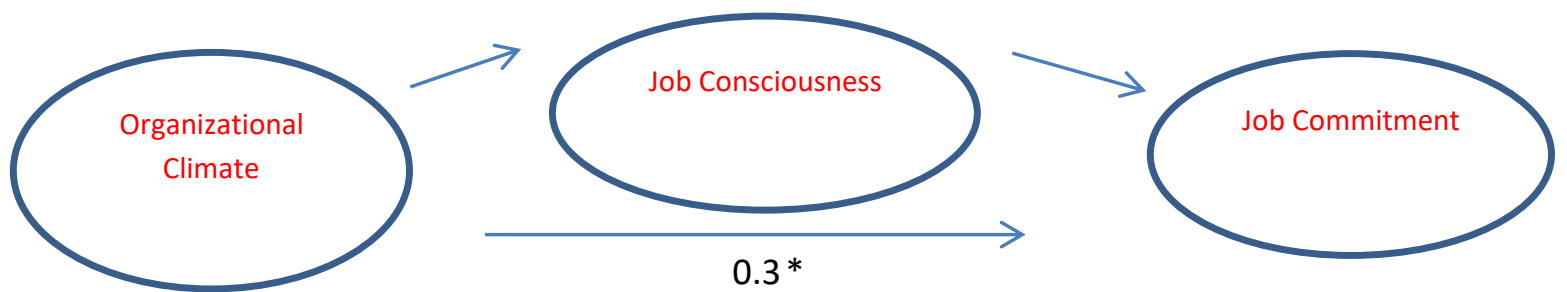

$* p<0 / 01$

Figure.2 Final communication variables model

In the next column of Table 2 shows that Chi-square fit model, along with other indicators are desirable. It should be noted, in the structural equation model, the Chi-square and indicators fitted to determine the status (approval or disapproval) will be the ultimate model. In this type of analysis is required, a non-significant Chi-square and indicators such as measures of Goodness of Fit Index (GFI), the Comparative Fit Index (CFI), Normative Fit Index (NFI) and Incremental Fit Index (IFI) when the upper 0/9 they are indicative of the desirability of the model. Root Mean Square Error of Approximation (RMSEA) as well as closer to zero indicates a desirable example. In addition, the indicators obtained from ideal conditions are present for the final research model.

\section{Discussion and Conclusion}

To achieve the purposes of this research and theoretical and experimental background according to the model were proposed with the simulator using path analysis. The researches of Saeedian and Moradi (9002); Barati et al (2010) instead of optical, as well as Mahdad et al (2012); Jackson (1999) and Archana (2004) in terms of their findings as a result of coordination with the main hypothesis of this plan, namely the existence of an intermediary role of conscience in the relationship between organizational climate and organizational commitment in Yazd Islamic Azad University employees. People with high job consciousness always concerned with work, job and their duties are correct. This concerns mainly the amount and manner of supervision and discipline of the society and the organization of individual stems. Job consciousness affects job performance. Also positive organizational climate may increase this effect. Thus, organizations and managers can assess the personality traits of their employees, especially their job consciousness, their organization in order to create a positive atmosphere. The organization includes many things are important for the organization's ethical climate and ethical behavior of employees is effective. Ethical climate of the organization include the perception of right and wrong in the work environment and organizational behavior norms for acceptance and rejection of the offer.

The second result of the project that there is a significant relationship between organizational climate and employee commitment to the organization in the Yazd Islamic Azad University, with findings from research Ghaseminejad and Siadat (2004); Noorbakhsh and Mirnadri (2005); Fooladvand(2007); Barati et al. (2010); Faghihi (2012); Mahdad et al (2012); Sistrunk (1989); Jackson (1999); Goleman et al (2001); Morris and Bloom (2002); Kick et al (2006); Ertürk (2007) and Chen and Chiu (2007) are the alignment and coordination. Organizational climate, organizational structure is considered to be objective. Since the members of the organization share common structural features, find common understanding that organizational climate forms. Several studies show that policies, programs and financial position of any organization suitable working environment does not become, but what the organization an ideal working environment makes employees feel about the workplace. The 
organizational climate is the same as the air in a room, we can not see or touch the organizational climate, but it surrounds us and everything that happens to affect and also of what is going on in the organization, the impact of accepts. Therefore, any organization, culture, traditions and special methods of operation on the make up of its atmosphere. Some organizations working atmosphere is dynamic and tolerant of others and some human and some are quite hard and cold. In the openness and good atmosphere, staff, job satisfaction and motivation are significant enough to overcome their problems. They have a driving force for organizing and keeping things moving organization. In addition, employees are proud to work with your organization. Staff working well with each other and the whole organization is doing. Organizational climate relates to determine measurable features a work environment that is directly or indirectly by those who work in this environment is perceived and assumes that the impulse and affect behavior, also the most effective and influential source for shaping the behaviour of acts. Organizational climate can be the result of leadership as manager. Effective management skills in motivating employees to meet the psychological needs of employees as a great achievement, power, etc. All of these factors contributes to the efficiency and effectiveness of staff and ultimately improve the efficiency and effectiveness of the organization.

In this study, was determined that the level of conscience of job commitment towards working for the organization in Yazd Islamic Azad University personnel is needed, because according to the data obtained between conscience and career commitment to the organization in Yazd Islamic Azad University personnel as well as a significant positive relationship is established. The results of the researches, Babaei and Momeni (2006); Saeidian and Moradi (2009); Barati et al (2010); Faghihi (2012); Archana (2004) are coordinated in some way with these findings. Human resources are the most important asset of any organization. Review and identify factors associated with those resources that can be found on the importance of effective organizational performance is becoming increasingly important. Improving job performance is one of the most important targets that are in the Organization managers because the upgrade provides productivity in society and promotion of the national economy and upgrading the quality of service and production organization will be. Job performance of the duties of the job he is doing. The performance of the activities have been defined, which is typically part of the job and the person's activities and should do it. The basic factors of the person's desire and ability in the performance and productivity of the individual have been introduced. In this way, the job conscience causes is in order and a sense of duty will be in people. Taking the concept of consciousness in organizations, according to ethics and human relations, because the ethics creating commitment and cause people to job duties and their behavior in the best shape and there are no external control of critical factors. The existence of job consciousness in an organization will increase productivity, sustainable development, human cultural development, management stability and economic order. Taking the concept of ethical and human consciousness in organizations actually look at the issue of work and organization. For professional ethical behavior leads to a commitment to duties in the best way and without external control, followed by improved results, to improve the community, inner satisfaction and peace of mind is one's conscience.

\section{Corresponding Author}

Saeed Vaziri Yazdi

Department of Educational Sciences, Yazd Branch, Islamic Azad University, Yazd, Iran

Email: s.vaziri@iauyazd.ac.ir 
INTERNATIONAL JOURNAL OF ACADEMIC RESEARCH IN PSYCHOLOGY

Vol. 2, No. 1, 2015, E-ISSN: 2312-1882 @ 2015 KWP

Islamic Azad University, Yazd Branch, Yazd, Iran

\section{References}

Archana, V. (2004). Occupational Stress and Social Support as Predictors of Organizational Commitment Psychological Studies. 49 (2-3), 202-204.

Babaei, M. A., Momeni, N. (2006) Relationship between emotional intelligence of managers and organizational climate. Iranian Journal of Management Science, Vol. I, No. 2.

Chiu, S. F., \& Chen, H. L. (2007). Relationship between Job Characteristics and Organizational Citizenship Behavior. Journal of Social behavior and personality. Vol. 33.

Ertürk, A. (2007). Increasing organizational citizenship behaviors of Turkish academicians. Journal of managerial psychology, Vol.22, No.3

Faghihi, F. (2012). The relationship between organizational climate and organizational commitment of teachers in primary schools for girls in the city of Varamin, MA thesis on the advice of Delavar and Saki.

Fooladvand, K. H. (2007). Relationship between organizational climate and mental health in staffs of hospitals in the city of Ilam. Journal of Ilam University of Medical Sciences. Volume XV, Number One.

Ghaseminezhad, A., Siadat, A. (2004). The relationship between organizational climate with job stress and its effects on high school teachers. Bimonthly Journal of Daneshvar. Shahed University. 11 years, No. 8.

Goodarzi, A., Gominian, V. (2002). Principles, fundamentals and theories of organizational climate. Esfahan publication of SID unit.

Birjandi, H. M. (2000). Career guidance and counseling. Tehran. Roodehen Azad University Press.

Jackson R. L. (1999). Transformational and Transactional Leadership in Division Administration at Three in Situations of Higher Education. Educational University of Cincinnati.

Majlesi, M. B. (1403 AH). Bihar al-Anwar, Beirut, Alvfa' Institute, Alsanyh.

Morris, A., Bloom, J. R. (2002) Contextual factors affecting job satisfaction and Organizational commitment in Community mental health centers undergoing system changes in the financing of care, University of California, USA. Hun, 4(2), 71-83.

Noorbakhsh, M., Mirnaderi, A. A. (2005). Relationship between organizational climate and job satisfaction in high school physical education teachers in Ahvaz. Olympic Journal. Year XIII, No. 1 (Series 29).

Saeedian, N., Moradi, M. (2009). The relationship between leadership style Bass with job consciousness and job commitment of managers in boys' high. Journal of Educational Sciences (Curriculum), Khorasgan Islamic Azad University. No. 22, pp. 140-119.

Sefidgar, H. (2009). Songs work in Azerbaijan, Tehran future plans.

Seidameri, M. H., Esmaeeli, M. R. (2010). The relationship between empowerment, organizational commitment, and job commitment in Tehran Department of Physical Education, Sport Management, Tehran University, No. 7, pp. 144-125.

Shafiabadi, A. (2012). Career guidance and counseling and theories of selected jobs. Tehran, Roshd Publication Institute.

Sistrunk, W. E. (1989), Relationship between the Leadership style of a junior high school Principle and the School climate. U.S. Mississippi. 


\section{INTERNATIONAL JOURNAL OF ACADEMIC RESEARCH IN PSYCHOLOGY}

Vol. 2, No. 1, 2015, E-ISSN: 2312-1882 @ 2015 KWP

Talebian, A. (2003). Assess the level of job consciousness and social factors affecting. PhD thesis of Sociology, Faculty of Social Sciences. Tehran University.

Zolfaghari, H. (2009). Great culture of Persian proverbs, Tehran, Moeen. 